\title{
In Conversation with Max Hamilton
}

The following is the second part of Brian Barraclough's interview with Max Hamilton. Part I appeared in the March Bulletin.

MH From Springfield I went to a Senior Lectureship at Leeds, in 1953, under Professor McCalman. The foundation professor had been Henry Dicks, but he had left after 18 months, in about 1948. I think the official reason was that his wife didn't like being in Leeds and wanted to get back to London. But there is no question that he had an awful lot of difficulties. Leeds had a surgical tradition, Moynihan was the great god. Not even a medical tradition, a surgical one! Psychiatry would never have got in unless the Nuffield Foundation had offered the money.

When I got there, McCalman had been trying to do a drug trial. I left Springfield just before May and Baker asked us: 'Would you do a trial of chlorpromazine for us?' I could never decide whether that was good luck or bad. Chlorpromazine was first tried out in Springfield but there was no control, no assessment, no analysis. If I had remained there it would have been done. At Leeds McCalman was comparing chlorpromazine, reserpine and placebo, and he had tried to produce assessment forms. It was coming to its end, unfortunately, when he asked me to give a hand. I looked at the data sheets and things went dark. In 1953 when chlorpromazine was introduced, there were probably only two psychiatrists capable of doing a controlled trial-Linford Rees and myself, and there was one capable of devising a rating scale-myself. Perhaps Linford Rees could have done, but I had certainly gone through the grind.

McCalman was ill with severe rheumatoid arthritis and high blood pressure and eventually had to go parttime. Professor Hargreaves arrived on the scene with a dowry: two big boxes, one containing a new anxiolytic, the other placebo. Miltown (meprobamate) had just been discovered. He said: 'Max, organize a clinical trial.' First I looked through rating scales of symptoms. None were any good for my purpose. So I devised an anxiety scale. There were two other nice things in that trial. One was finding how important suggestibility is and how patients respond to comfort and reassurance. I ensured that the patients were suffering from an anxiety neurosis. They had the pills and were seen every week. But for the first fortnight they were all on placebo, which we knew, but they didn't. One patient said: 'I can't stand the strain of this terrible drug', and had to go out. After two weeks, half were randomly changed to the active drug. We followed them up for three weeks. I had my rating scale. I also used an analogue scale and found it gave me exactly the same answers as the other rating scale, so I didn't bother with it again. If I had had sense I would have done. But an analogue scale was old hat. They were invented before World War I. I had to analyse two treatments, in a two-way factorial design with unequal numbers in the cells. I think it was the first time in psychiatry. The assessment was from week 2 to week 5. The patients who were on placebo for five weeks continued to improve. I suggested in the paper that patients with anxiety ought to be four weeks on placebo before anxiolytics. Somebody re-discovered that a few years ago.

The trial was over. We still had the patients, we still had to see and treat them. Then something profoundly interesting happened. Two or three of these patients, carefully selected and diagnosed as anxiety states, became severely depressed and had to be given ECT, and responded very well. That set me thinking. About this time I got fed up with a heavy clinical load. I had gone to an academic department to do research. I had got a taste of it and wanted to do more, but Hargreaves said I couldn't be relieved of any duties. I managed to get a part-time grant and he collected further money so I could do a full-time research job for a couple of years. But the University said, according to him, they could not let me off because they would not be able to get a temporary replacement. I was faced with a dilemma and resigned to take the research job.

BB How old were you?

MH 45.

BB An adventurous thing to do?

MH I suppose so, but I always felt that if the worst came to the worst I could get an NHS consultant job. I got Jack White at Stanley Royd Hospital to co-operate with me. I devised a rating scale for depression, played around with it, tested it out, and then started work. The depression rating scale came after the anxiety scale and is much better. Both scales have deficiencies, but they were carefully designed, and sophisticated, even though I say it myself. You see, a scale must not be too long. The Wittenborn scales have 150-250 items. That is ridiculous, useless. But it mustn't be too short or it loses reliability. The ideal number of items is somewhere between 10 and 20 . With all-purpose scales, most items are inapplicable. They waste time and are a source of error because of the temptation to put something in if in doubt. I devised these scales specifically-one for anxiety, one for depression - and I didn't deal with any other symptoms. I devised them so they would be easy to use, and they were about clinical matters which 
clinicians were interested in, and that is why they endure. If you have a clinical interview with a patient you can fill it in. It doesn't take any time, it's not complicated. Americans say there are too many somatic symptoms and not enough psychological ones. My answer to that is 'That's what my patients are complaining about-that's what they are suffering from, that is what is a burden on them, and that is what I am measuring - the burden of illness.'

BB Do you know how many times it has been cited?

MH I don't know, about 700 in 20 years, according to Science Citation Index, an incredible figure. It has now reached the point where people refer to the Hamilton scale without giving the reference. Now there's glory for you.

BB Like when a vacuum cleaner becomes a Hoover. What do you think of the PSE?

MH It's magnificent as a research instrument, but it is not practical. It can be used only by a research unit. It is superb if you want to do something on schizophrenia, but the PSE cannot be used by practising clinicians and that is its disadvantage.

BB Do you think it would be possible to have a scale for schizophrenia of the kind that you devised for depression?

MH While I had this research job I compared chlorpromazine with placebo. I also crossed it with extra occupational work and social rehabilitation against none of these. I was looking for the interaction between psychological and drug factors, the first time anyone had done this in a planned trial. I started with the hypothesis that the drug facilitated the patient's response to social influences. It doesn't. I found that patients improved with the drug, and they improved if you gave them extra social therapy. But both together didn't have any additional effect. If anything, the drug seemed to inhibit the effect of social influences. For that trial I picked out a set of items which were applicable for chronic schizophrenics from the Lorr scale. There were about 20. I have used that scale on two or three occasions since then. It is effective enough for chronic schizophrenia. It is a set of items on hallucinations, delusions, autism, things like that and a bit about mood. It is not good, but it does the job.

BB What followed the two years of research?

MH When it was coming to an end Hargreaves got me a job for a year in the NIMH Clinical Neuropsychopharmacology Research Centre in Washington. It had begun to get around America that there were new drugs coming from Europe. The people who gave funds to the NIMH wanted to set up a clinical research unit. They looked around for somebody to head it and got Elkes from England. He was in difficulty when he wanted someone to do clinical research because he couldn't find any clinicians in the USA - and that's how I got the job.

I was in charge of a unit at St Elizabeth's Hospital. What did I do? That is a tale in itself. I found half a dozen people who were officially doing clinical research. A medical man conscripted into the army (there was still conscription then) can go into public service as an alternative. For psychiatrists this meant St Elizabeth's. Most were busy getting psychoanalysed and preparing for private practice, so their research projects ... you can imagine what they were like. Elkes said: 'Find out what everybody's doing, take your time, and then organize things.' They were all busy on the most dreadful things. There was I, responsible, but he hadn't given me authority. He had not told anybody that when Max says jump, you jump! I was in the situation where nobody was going to take any notice of this damned Englishman, and he wasn't even an analyst; he was an 'administrator'. They divided psychiatrists into therapists and administrators. It soon became fairly obvious that nothing was going to come of it. At this point I said: 'Look, if you just change it round and do it this way we can get a job done'; I elaborated my previous trial of drugs against placebo on the one hand and rehabilitation and nonrehabilitation on the other.

BB Did you get much done?

MH I got that trial done, essentially. I was also interviewing people about my depression scale and trying to see if I could get some work going on depression. I went around with my scale and it created a tremendous wave of apathy. They all thought I was a bit mad. Eventually I got it published in the Journal of Neurology, Neurosurgery and Psychiatry. It was the only one that would take it. And now everyone tells me the scale is wonderful, I always remember when it had a different reception. This makes sure I don't get a swollen head.

I should mention that fundamentally my interest is as a clinician. Long ago, I came to the conclusion that ultimately the discoveries in psychiatry were going to be made by biochemists. Before World War II, it was the biochemistry of urine; after the War it has been the biochemistry of blood and CSF. But until we get down to the biochemistry of neurones, we are not going to get anywhere. That is what we are doing now.

I was faced with the fact that if I wanted to do research, biochemistry was the thing. But I wasn't a biochemist. But without the clinician the biochemist is blind. Unless they can link their work up to clinical phenomena, it doesn't mean a thing. So the clinician is still critical. He is the man who leads the biochemist through the jungle. Systematic and subtle clinical studies must underlie all biochemical research. That is one reason why such wonderful biochemical research in America is nullified by inadequate clinical work.

BB On your return you had a job at Leeds as MRC 
External Scientific Staff?

MH Yes, officially attached to the Department of Psychiatry, but for clinical work to Stanley Royds Hospital, Wakefield. I had worked with one of the previous consultants, but things had changed and it was not possible to return to the previous collaboration. I was stuck with the problem of getting clinical work. The local out-patients and domiciliaries were all buttoned up so I came back to Leeds to start an outpatient session. I worked away but it was very unsatisfactory. I was the new consultant who comes in and everybody has to make room. If they are unwilling, he doesn't get patients and has a bad time. I managed to get some work done, but it was slow and difficult.

After I had collected data on 50-odd patients, I went to the computing laboratory and asked could it be analysed. They said, 'Yes, of course'. 'How do I get it done?' 'If you just study this book on how to write programmes, we will teach you how to punch them onto tape and how to use the computer.' It is amazing what you can do when you have to. I had to learn to write and test programmes and do my own computing. And that was a profoundly significant experience for me. I had always tried to think clearly because, being an obsessional, uncertainty was difficult. But here for the first time I came up against a situation where clarity and precision of thinking is absolutely necessary. I had learned in 1943 that an experiment is not done by going around with a vague question mark looking at the world. You have to have a definite hypothesis and an experiment that will get an answer. But when writing programmes I had a new order of clarity and precision. For the first time I looked critically at the way people were arguing, and realized how vague were people's ideas, how discussions are often beside the point. I was surprised. Now when I listen to arguments about politics or religion, they seem a waste of time. In psychiatry there are no clearly defined entities. We can't talk about schizophrenia or depression or anxiety states as if you can define them clearly. This is the trouble of attempting to apply mathematical logic to the real world. That does not mean that you can't have clear thinking. Even if there is vagueness, your thinking can still be clear. It is like Fisher's remark about experimental results-you can never prove anything absolutely, there is always uncertainty, but you can specify the uncertainty.

BB How many years did you work for the MRC?

MH From 1960 to 1963 -three years.

BB What did you achieve?

MH Damned little. I didn't have enough patients, and I hadn't got very far, and I didn't publish much in that time. However, I had laid the foundations for the work, so when the Chair came up I applied. I didn't think I would get it because Leeds Infirmary was notoriously
anti-Semitic. I remember McCalman said he had heard one consultant boast he had never had a Jew higher than a houseman. But it was in the hands of the University as well as the Infirmary. Compared with the other two candidates I had a better research record. The other two candidates, incidentally, were Frank Fish who got Liverpool and John Hinton, who went to Middlesex. I got the job and thought that now I had a department with beds research should be much easier, and in some ways it was and in some it wasn't. Now I was involved in organizing an undergraduate department with minimal staff and no funds, without a research tradition and with all sorts of restrictions. But I managed something.

In 1963, Leeds was second-bottom in the percentage of medical students who took up psychiatry. When I left it was third from the top. And I think this was the result of my policy. Very few medical students are going to become psychiatrists, therefore it is no good teaching them psychiatrists' psychiatry. You have to teach the psychiatry of the GP and the general physician and surgeon. We taught them about the common disorders. By the time they finished, they were running out of their ears with depressions and anxiety states. The way psychiatry impinges on you in practical life. I always gave the introductory lecture and pointed out that as medical undergraduates most of their time was spent learning how to make a diagnosis. But one of the facts to be faced was that whether they were in general practice or hospital medicine, diagnosis became a trivial problem because most of their patients had been diagnosed anything from two weeks to twenty years before, and of those who had not been diagnosed, the majority were straight-forward. All the fuss is on a tiny percentage of cases, and between you, me and the postman, it generally doesn't make much difference either. Most doctors in the past have had to spend much of their time with patients for whom they could do little. (Big smile from the students.) What is more, they still do. (Smile is a little less.) What is more important, they always will. And that wiped the smile off their faces. Once medicine solves the problem, it doesn't occupy our time. So what is your time occupied with? The patients for whom you can do little or nothing. And that is what your job is and that is what you are going to spend your life doing. It shakes them. And we are going to teach you about the problems of patient management. That is what we taught.

We also took them into mental hospitals for a short period where they had more contact with patients than at any other time in their medical career. And I said to them, 'You are going there, not because I want you to learn psychiatrists' psychiatry, but because everybody should know what goes on in a mental hospital. You are going to be asked about this by patients and their 
relatives. I don't do surgery, but it is important that I should know what goes on in an operating theatre. That became the most popular part of the course, and I think the reason why we went up from the bottom to near the top.

BB What about postgraduate responsibilities?

MH Henry Dicks had started a DPM, which ran every two years-a two-year course. This was obviously useless. We had to run a course every year, which meant doubling the work. In a provincial medical school and in provincial hospitals up north, you have to attract trainees or they will not come. Having been a mental hospital doctor, I still felt part of that community; my attitude was that the Department of Psychiatry will always be regarded as an ivory tower so it is important to have strong links with the mental hospitals because that is where the patients are! 1 saw my position as a focal point for the psychiatry of the Region. Our job was to provide training which would attract staff to the hospitals. They had the patients, and I therefore wanted all my staff to have honorary attachments so they would have access to patients by right. In exchange, I offered consultants an opportunity to work in the University department and to teach students.

We started an MSc course which included research methodology for psychiatric social workers and even when everybody said PSW is out, old-fashioned, we kept the course going. I also said to the Department of Psychology: 'Let's offer jointly an MSc in clinical psychology.' Eventually we were the biggest postgraduate department in the medical school, with students in clinical psychology, psychiatric social work and postgraduate psychiatry-roughly 20 in each.

BB And what about research in this busy life?

MH That was done in the interstices. I encouraged other people to do things and a small amount of work came out of the department every so often.

BB What was the theme?

MH There wasn't one in that sense. If you haven't full-time people and equipment, you have to use ingenuity. My example of a simple ingenious idea which yields dividends is the one that Clive Tonks had. The majority of the parasuicides were young women. He asked them the time during the menstrual period they had made their attempt. Those who did not have pre-menstrual tension had a preponderance of attempted suicide a week before the menstrual period-the opposite of what you would have expected. A research fellow (Stephen Tyrer) compared the psychological aspects of women who have hysterectomy for cancer with those who have it for functional disorders. He produced a questionnaire under my guidance and collected the information and got a nice paper out of it.

BB You have always been interested in psychology and were made President of the British Psychological
Society.

MH I had a greater reputation in psychology than in psychiatry, until recently. 1 joined the BPS during the war. I kept up my contacts and almost all the work I have done has required methodology developed by psychologists. I argued that psychologists have something to contribute to psychiatry. That is why, for example, one of our registrars was one of the first psychiatrists to try out behaviour therapy.

Psychology is a basic science for psychiatry. Psychologists have a sophistication in research and in theorizing which is lacking in our subject. When I started to read clinical psychiatry the stuff in the textbooks had an extraordinarily oid-fashioned air about it. We have disorders of affect and the schizophrenias, which are primarily disorders of thinking. What about disorders of will? They are the psychopaths. Here are the three faculties-all the way from Aristotle. But even within one illness, what do we say about the symptoms of depression or mania? There are disturbances of affect, of thought, and of behaviour. Here are the old Aristotelian faculties still present and we still think in these terms. The psychology of psychiatry is antediluvian-very odd. The psychologists have been looking at faculty theory for a long time, very carefully and we ought to take account of them.

BB Why haven't they made more impact?

MH Difficult to answer that. Let me give you an analogy. I once picked up an early issue of the Lancet, and noted an editorial introducing a new series of articles: doctors ought to know something about chemistry and they were going to provide a series of articles. And do you know what the first one was? How to make oxygen from potassium chlorate! Now I think you will agree that the physician practising at that time would have looked at it and thought 'what a lot of nonsense'. It has taken time, but now you can't study medicine without chemistry. A similar problem occurred when Harvey discovered the circulation of the heart. Since all the practitioners were worrying about the balance of the humours, would it matter whether the heart pumped or not? It was irrelevant. They didn't see the connection.

We have to recognize that psychologists tended to start on simple things like reaction times. Obviously of little relevance. By and large it never had much impact. And when psychologists made contact with clinical work, psychiatrists thought of them the way they thought of clinical pathologists. Let's order a blood test or an intelligence test.

BB But psychiatrists have adopted behaviour therapy techniques from psychologists because they are effective.

MH But who developed them? Psychologists. And this was on the basis of learning theory and animal behaviour. The contribution, therefore, is in an outlook, the application of scientific method. The work, for 
example, that Robert Kendell has been doing on the classification of schizophrenia, is based on the psychometric approach. Who developed it? The psychologists. It is in the fields of methodology, theory and sophisticated scientific outlook that the psychologists have important contributions to make.

BB You have written six books?

MH Actually not so many. I have written two on my ownone on psychosomatics, ${ }^{1}$ the other on the methodology of clinical research. ${ }^{2}$ It has always been regarded rather snootily by the College since it came into competition with Peter Sainsbury's volume.

BB What about the other four?

MH I once edited Readings in Abnormal Psychology where I dug out a series of papers which I thought formed an important background to our thinking. The most important thing now is to keep three out of four of Frank Fish's books going-Clinical Psychopathology, ${ }^{3}$ Schizophrenio and An Outline of Psychiatry.' I got into that accidentally. We recommended them for our postgraduates, but they complained that they weren't available, so I wrote to the publishers who asked me to prepare new editions. Since I knew Fish weil, I was pleased to do so.

BB What do you think about the state of current psychiatric research?

MH It's active, alive and go ahead. The British Journal of Psychiatry and Psychological Medicine are so full of meat 1 can't glance through them and think, 'Well there's a couple of articles worth looking at'; there are so many that are so good. It is impressive. And the trends are interesting - there is so much work on classification of disorders, discriminant function, psychometric applications. What we are doing is worthwhile. Then the work on social psychiatry, there is the work you did on old people and on parasuicides by Kreitman, examples of important work-characteristically British. We are doing biochemical research as well. We can't hope to compete with the Americans. Psychiatry in this country follows the British tradition. There is good, sound clinical basis and it isn't rigid or limited. It is not middle of the road but on a broad front, covering all fields. I believe the fundamental discoveries are going to come in biochemistry.

But it is a long way from the problem of management of patients; patients are human beings with human feelings, who live in a social environment with personal relationships and all these have to be dealt with and taken into account. I will give you an example. I found I became successful clinically because early on I cottoned on to the fact that it is not enough to see the patient; the relatives need treatment, comfort, reassurance, support, help and I spend almost as much time with relatives as with my patient. It makes a lot of difference. The result is that my patients take their drugs and come for follow-up. If they don't turn up I send a postcard: 'Sorry you couldn't turn up-1 am going to be there tomorrow'-and I go round to the home the next day. I used to be afraid that I would have the door slammed in my face. Nothing of the sort-I was invited in and offered tea and cake. My capacity for follow-up depends on my capacity for tea and cake!

\section{References}

' HAmilton, M. (1955) Psychosomatics. London: Chapman \& Hall. 2 _- (1974) Lectures on the Methodology of Clinical Research. Edinburgh: Churchill Livingstone.

${ }^{3}$ FISH, F. (1967) Clinical Psychopathology: Signs and Symptoms in Psychiatry. Bristol: Wright.

4 (1962) Schizophrenia. Bristol: Wright.

3 (1968) An Outline of Psychiatry for Students and Practitioners. Bristol: Wright.

\section{A Clarification}

A number of readers appear to have misunderstood the article 'Psychiatric Testimony-Who Can Give it and When?' by Diana Brahams (Bulletin, July 1982, 6, 121-2). All but the end of this is in fact a fair account according to the trial transcript of the judgment given in the Court of Appeal by Lord Justice Ackner touching on two matters: who can be called to give medical evidence (of insanity), and whether an expert who had not professionally examined a witness, but simply, like the jury, has seen his behaviour in the witness box, can testify on the likelihood of his veracity. On the first matter the lawyers at the trial were confused as to the difference between a psychologist and a psychiatrist, and what kinds of specialist might appropriately help the Court from the witness box. On the second, the Court took the view that it would usurp the function of the jury to allow such evidence. In this case the witness was capable of giving reliable evidence and it was not appropriate to call a specialist to warn the jury that the witness might not choose to tell the truth.

Only in the final two paragraphs of her article did Mrs Brahams express her own opinion, endorsing that of the Court, that "courts should guard against the unnecessary "proliferation of expert witnesses, and the exploration of irrelevant collateral issues" ' (per Ackner, L.J.). In so far as our editing of this article, in particular the deletion of the subheading 'Comment' before the final paragraphs, may have led to misapprehension, we wish to apologize to readers, to Mrs Brahams and to Mr B. L. Irving, the psychologist in the case, for any confusion or embarrassment. 